\title{
An in vitro Study of Effect of Salt and Sugar on Bacterial Species
}

\author{
S. Nithish*, M. Anvesh, A. Rishitha Sanjana, R. Usha Rani, R. Pranay, A. Vydhika, \\ P. Nikitha, D. Sowjanya, M. Ramya, K. Shiva and T. Indira Priyadarshini
}

Chilkur Balaji College of Pharmacy, Aziz Nagar, Moinabad, Hyderabad, Telungana, India

*Corresponding author

\section{A B S T R A C T}

Keywords

Zone of Inhibition (ZOI), Zone of Exhibition (ZOE), Streak control, Antibiotic Resistance, Phyto chemicals

\section{Article Info}

\section{Accepted:}

10 January 2021

Available Online:

10 February 2021
The Golden Era of microbiology is marked with the discover of almost all the antibiotics which helped in treating several diseases. But due to development of bacterial resistance against susceptible antibiotics, development of new antibiotics is in race in present day scientific and research field. Holding the truth (some consider as truth) that history would repeat after reaching a peak point in the development over time, many researchers are looking back at the history of how humans combated against undiscoverable (at that time) pathogens. In this context, the use of Phyto chemicals (plant extracts) \& other naturally occurring resources as antibiotics in the history, gave a different view point in developing new antibiotics. Several plant extracts are already proven as potent bactericidal \& bacteriostatic agents against certain bacterial species. Use of several other Phyto chemicals \& natural products as potent antibacterial agents are under investigation. Few of the proven natural products \& Phyto chemicals having antibiotic property includes: Honey', Mentha arvensis L., Cordia verbenacea DC, turmeric, curcumin (active ingredient of turmeric) etc. This invitro study is an attempt in demonstrating the effect of $\mathrm{NaCl} \&$ sucrose (solutions at different concentration range) on bacterial growth activity.

\section{Introduction}

We know that salt and sugar (sucrose) are used as preservatives from ancient days. If the salt and sucrose have an antibacterial activity for which it can be used as preservative, then it can also be used in treating several superficial bacterial infections. But the same is not clinically used or approved. A trial to prove its potency as anti-bacterial agent is done using well diffusion technique. Both the salt and sucrose are prepared in the form of solutions of different concentrations to test for its peak activity at a particular concentration and also to determine the concentration range vs antibacterial activity of both the solutions. It is assumed that at certain concentrations of the solution, the bacterial growth may be encouraged (due to which the product prepared using these as a preservative gets contaminated). Any of the above assumed activity is measured in terms of diameter of Zone of Inhibition/ Exhibition formed in well diffusion technique.

This in vitro study is to determine the concentration of salt $(\mathrm{NaCl})$ and sucrose at which peak antibacterial activity is observed, 
however, this is to be tested further in animal model to prove its clinical usage. In the sideways, this is also to determine the concentration at which it has a minimal antibacterial activity in favour of not to use in food industries as preservatives.

Both the $\mathrm{NaCl} \&$ Sucrose solutions of different concentrations are tested in vitro for its activity on Staphylococcus aureus \& Escherichia coli. If the concentration of solution has an antibacterial activity (bacteriostatic or bactericidal) then zone of inhibition (ZOI) is developed \& if the concentration is enhancing the growth, then zones of exhibitions (ZOE) are developed ${ }^{4}$. Both the zones either inhibition or exhibition are measured in mm using a simple scale \& reported as diameter of the zone of inhibition or exhibition $($ diameter in $\mathrm{mm})=$ Diameter of zone observed in $\mathrm{mm}$ - diameter of the well in $\mathrm{mm}$. Since the wells made using a sterile cork borer of diameter $7 \mathrm{~mm}$, the diameter of the well is $7 \mathrm{~mm}$ which makes the calculation as

Diameter of the Zone of inhibition or exhibition $(\mathrm{mm})=$ diameter of the zone produced $(\mathrm{mm})-7 \mathrm{~mm}$.

Zones are measured at $24 \mathrm{hrs}, 48 \mathrm{hrs}$ and 72 hrs to check the activity for a longer duration of time.

\section{Materials and Methods}

\section{Bacterial strains}

Staphylococcus aureus (ACTC 10788) \& Escherichia coli (NCTC 12923) are used in testing the activity of different concentrations of $\mathrm{NaCl} \&$ Sucrose solutions.

\section{Medium}

HiMedia labs manufactured Nutrient Agar (M001/ ISO 17025:2005) is used throughout the study for testing the antibacterial activity.
HiMedia labs manufactured N. Broth (M002/ ISO 17025:2005) is used in preparing the sub culture of the main culture.

\section{Solutions of Nacl \& Sucrose}

Both the $\mathrm{NaCl} \&$ Sucrose solutions used in the study are prepared using laboratory grade $\mathrm{NaCl} \&$ Sucrose in a concentration range of $1 \%, 3 \%, 5 \%, 7 \%, 9 \%, 10 \%, 11 \%, 13 \%, 15 \%$, $17 \%, 19 \%$ \& $20 \%$ using distilled water on the day of the experiment by dissolving $0.1 \mathrm{gm}$, $0.3 \mathrm{gm}, 0.5 \mathrm{gm}, 0.7 \mathrm{gm}, 0.9 \mathrm{gm}, 1.0 \mathrm{gm}, 1.1$ $\mathrm{gm}, 1.3 \mathrm{gm}, 1.5 \mathrm{gm}, 1.7 \mathrm{gm}, 1.9 \mathrm{gm}, 2.0 \mathrm{gm}$ of $\mathrm{NaCl}$ or Sucrose in $10 \mathrm{ml}$ of distilled water respectively.

\section{Distilled water}

Normal tap water is distilled using distillation apparatus. The required quantity of distilled water is collected on the previous day of the experiment (a day before) in a beaker \& the opening is covered with a polythene cover $\&$ stored in a sterile environment.

On the day of the experiment, the stored distilled water is heated on a heating mantle till it reaches its boiling point. The water is boiled for approximately 30 mins and then used in the study as per requirement.

Note: The distilled water which is properly sealed and stored in a sterile environment is again heated on the day of experiment to ensure that no microbial impurities are present in the study materials.

\section{Sterilisation}

All the glassware used \& the medium prepared are sterilised using autoclave. All the equipment is autoclaved at $15 \mathrm{lbs}$ pressure for 25 mins or $14 \mathrm{lbs}$ for $35 \mathrm{mins}$ or $13 \mathrm{lbs}$ for 45 mins. 
To ensure sterility even while medium transfer \& in streaking environment, the processes are carried out in laminar air flow chamber which is priorly cleansed with Dettol antiseptic liquid solution \& then exposed to UV light for15- 20 mins before its usage.

\section{Evaluation of MIC}

$\mathrm{NaCl} \&$ sucrose solutions are prepared using heated distilled Water. The glassware \& the medium prepared are autoclaved as mentioned above. In aseptic conditions/ environment (priorly cleansed \& UV treated Laminar air flow chamber) agar plates are prepared.

Before testing the antimicrobial activity of solutions, the bacterial streak plates (represented in figure 1) are prepared using streak plate technique to get individual colonies of the bacterium. Streak plate is prepared by taking a sterile inoculating loop full of liquid culture prepared using N. Broth the previous day, which is prepared using standard bacterial strains (as mentioned in the Bacterial Strains Section of Methodology).

A single isolated colony in the streak plate is selected to use in for the well- diffusion method. Using sterile cotton swab, the selected single colony is lifted \& is streaked on the fresh agar plate prepared.

The streaking is done in a continuous fashion twice for single uplift of colony by rotating the agar plate by $90^{\circ}$ after first streak is completed.

Care is taken to maintain the continuity of streak without lifting the swab till the streak is completed \& even the face of cotton swab is not altered, ensuring that the face of swab lifted the colony is in contact with the fresh sterile Agar plate on which the well- diffusion is being carried out.
After streaking the single colony of a bacterium on the entire solidified agar medium, wells are made using a sterile cork borer that makes a well of diameter $7 \mathrm{~mm}$.

3 wells per plate are made. Each well is filled with $20 \mu$ lit using micropipette with either $\mathrm{NaCl}$ or Sucrose solution of particular concentration.

\section{Study design}

A total of 10 agar plates are prepared in each batch (for each organism). 1 plate is used as control \& the other 1 plate is used as organism growth control. Control plate is to ensure no contamination during the study, represented in figure 2 at $24 \mathrm{hrs}$ as $\mathrm{A}$, at 48 hrs as B, at $72 \mathrm{hrs}$ as C. Organism growth control plate is the one in which only streaking is done using cotton swab to ensure the proper uniform growth of the bacterium. S.aureus growth control represented in figure $2 \mathrm{a} \&$ E. coli in figure $2 \mathrm{~b}$ at $24 \mathrm{hrs}$ as A, at 48 hrs as B, at $72 \mathrm{hrs}$ as $\mathrm{C}$.

On the remaining 8 plates, $1 \%, 3 \%, 5 \%, 7 \%$, $9 \%, 10 \%, 11 \%, 13 \%, 15 \%, 17 \%, 19 \%$ \& $20 \%$ $\mathrm{NaCl} \&$ Sucrose solutions are incorporated into each well as 3 different concentrations of either $\mathrm{NaCl}$ or Sucrose Solutions in the 3 wells of each plate.

All the 10 plates are properly sealed \& kept in incubator at $37^{\circ} \mathrm{c}$ for $72 \mathrm{hrs}$ and ZOI or ZOE are measured \& noted at $24 \mathrm{hrs}, 48 \mathrm{hrs} \&$ 72hrs (Fig. 11).

\section{Results and Discussion}

\section{Staphylococcus aureus}

None of the $\mathrm{NaCl}$ solution developed ZOI. Ratherthey developed ZOE (as seen in figure 3 at $24 \mathrm{hrs}$ as A, at $48 \mathrm{hrs}$ as B, at $72 \mathrm{hrs}$ as C) 
at concentrations of $17 \%, 19 \%$ \& $20 \%$ which is very minimal at $48 \mathrm{hrs}$ but increased a little at $72 \mathrm{hrs}$ to a range of $5 \mathrm{~mm}$ for $17 \%, 11 \mathrm{~mm}$ for $19 \%$ and $7 \mathrm{~mm}$ for $20 \%$. In case with Sucrose solutions, $7 \%$ and $10 \%$ concentrations developed unclear ZOI at 48 hrs but clear ZOI at $72 \mathrm{hrs}$ which measured $12 \mathrm{~mm}$ for $7 \%$ \& $11 \mathrm{~mm}$ for $10 \%$ concentration, as seen in figure 4 at 24 hrs as
$A$, at 48 hrs as B, at 72 hrs as $C$. The inhibition/ exhibition curves of these concentrations against Staphylococcus aureus are shown in figure $5 \& 6$.

\section{Escherichia coli}

None of the $\mathrm{NaCl}$ solutions developed either of the zones.

Table.1 Results of all the concentrations of both $\mathrm{NaCl} \&$ Sucrose solutions at 24, $48 \& 72 \mathrm{hrs}$

\begin{tabular}{|c|c|c|c|c|c|c|c|c|}
\hline \multirow[t]{2}{*}{ Organism } & \multirow{2}{*}{$\begin{array}{c}\text { Solution } \\
\text { of }\end{array}$} & \multirow[t]{2}{*}{$\%$ Concentration } & \multicolumn{3}{|c|}{ ZOI(in mm) } & \multicolumn{3}{|c|}{ ZOE(in mm) } \\
\hline & & & $24 \mathrm{hrs}$ & $48 \mathrm{hrs}$ & $72 \mathrm{hrs}$ & $24 \mathrm{hrs}$ & $48 \mathrm{hrs}$ & $72 \mathrm{hrs}$ \\
\hline \multirow[t]{24}{*}{ S. aureus } & \multirow[t]{12}{*}{$\mathrm{NaCl}$} & $1 \%$ & - & - & - & - & - & - \\
\hline & & $3 \%$ & - & - & - & - & - & - \\
\hline & & $5 \%$ & - & - & - & - & - & - \\
\hline & & $7 \%$ & - & - & - & - & - & - \\
\hline & & $9 \%$ & - & - & - & - & - & - \\
\hline & & $10 \%$ & - & - & - & - & - & - \\
\hline & & $11 \%$ & - & - & - & - & - & - \\
\hline & & $13 \%$ & - & - & - & - & - & - \\
\hline & & $15 \%$ & - & - & - & - & - & - \\
\hline & & $17 \%$ & - & - & - & - & * & 5 \\
\hline & & $19 \%$ & - & - & - & - & * & 11 \\
\hline & & $20 \%$ & - & - & - & - & * & 7 \\
\hline & \multirow{12}{*}{ Sucrose } & $1 \%$ & - & - & - & - & - & - \\
\hline & & $3 \%$ & - & - & - & - & - & - \\
\hline & & $5 \%$ & - & - & - & - & - & - \\
\hline & & $7 \%$ & - & $*$ & 12 & - & - & - \\
\hline & & $9 \%$ & - & - & - & - & - & - \\
\hline & & $10 \%$ & - & $*$ & 11 & - & - & - \\
\hline & & $11 \%$ & - & - & - & - & - & - \\
\hline & & $13 \%$ & - & - & - & - & - & - \\
\hline & & $15 \%$ & - & - & - & - & - & - \\
\hline & & $17 \%$ & - & - & - & - & - & - \\
\hline & & $19 \%$ & - & - & - & - & - & - \\
\hline & & $20 \%$ & - & - & - & - & - & - \\
\hline \multirow[t]{6}{*}{ E. coli } & \multirow[t]{6}{*}{$\mathrm{NaCl}$} & $1 \%$ & - & - & - & - & - & - \\
\hline & & $3 \%$ & - & - & - & - & - & - \\
\hline & & $5 \%$ & - & - & - & - & - & - \\
\hline & & $7 \%$ & - & - & - & - & - & - \\
\hline & & $9 \%$ & - & - & - & - & - & - \\
\hline & & $10 \%$ & - & - & - & - & - & - \\
\hline
\end{tabular}




\begin{tabular}{|l|l|l|l|l|l|l|l|l|}
\hline & $11 \%$ & - & - & - & - & - & - \\
\hline \multirow{5}{*}{} & $13 \%$ & - & - & - & - & - & - \\
\hline & $15 \%$ & - & - & - & - & - & - \\
\hline & $17 \%$ & - & - & - & - & - & - \\
\hline \multirow{5}{*}{ Sucrose } & $19 \%$ & - & - & - & - & - & - \\
\hline & $20 \%$ & - & - & - & - & - & - \\
\hline \multirow{5}{*}{} & $1 \%$ & - & - & - & - & - & - \\
\hline & $3 \%$ & - & - & - & - & - & - \\
\hline & $5 \%$ & - & - & - & - & - & - \\
\hline & $7 \%$ & - & - & - & 18 & 18 & 18 \\
\hline & $9 \%$ & - & - & - & 26 & 26 & 26 \\
\hline & $10 \%$ & - & - & - & 13 & 13 & 13 \\
\hline & $11 \%$ & - & - & - & - & - & - \\
\hline & $13 \%$ & - & - & - & 5 & 13 & 13 \\
\hline & $15 \%$ & - & - & - & 8 & 13 & 13 \\
\hline & $17 \%$ & - & - & - & - & - & - \\
\hline & $19 \%$ & - & - & - & 28 & 33 & 33 \\
\hline & $20 \%$ & - & - & - & - & - & - \\
\hline
\end{tabular}

zone presented is very small in diameter \& is unmeasurable no zone is observed

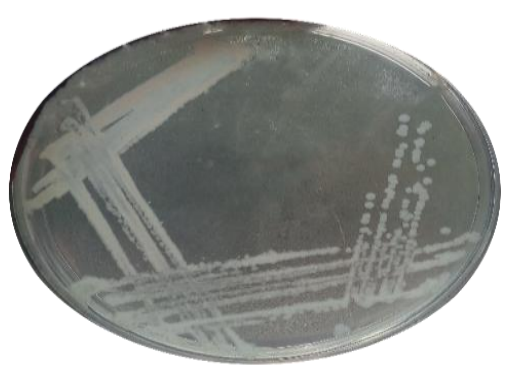

Figure 1: Streak plate of E. coli

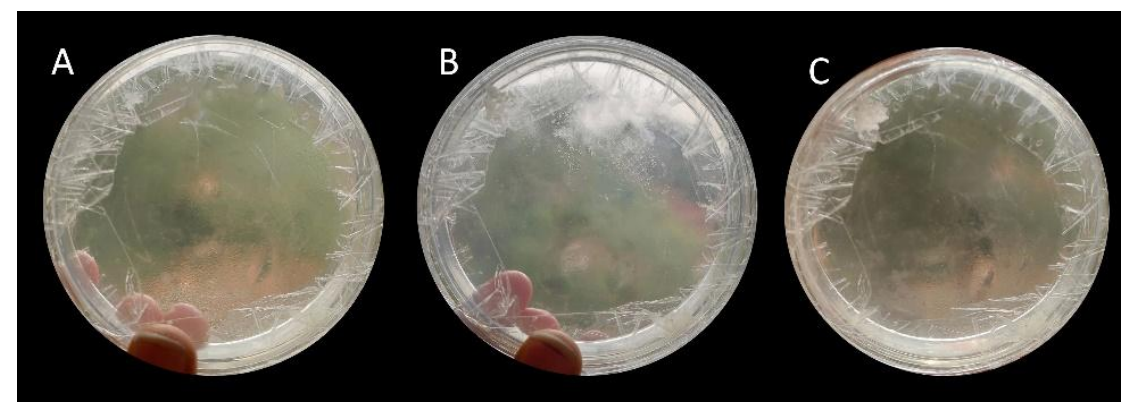

Figure 1: CONTROL PLATE AT 24 hrs (A), 48 hrs (B), 72 hrs (C)

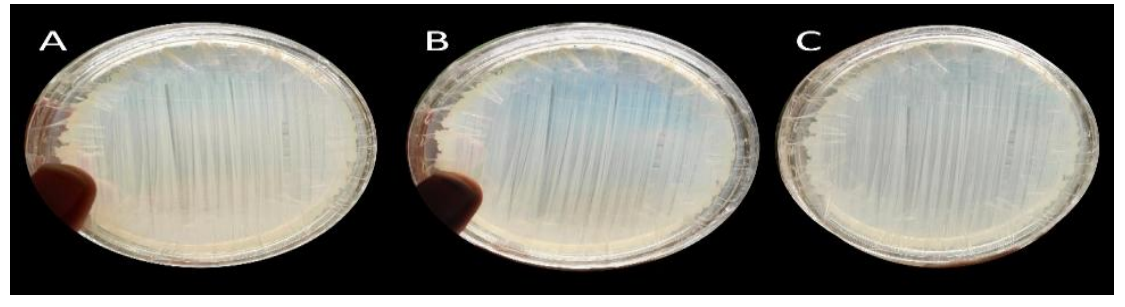

Figure 2a: Staphylococcus aureus Growth control plate at 24 hrs (A), 48 hrs (B), 72 hrs 


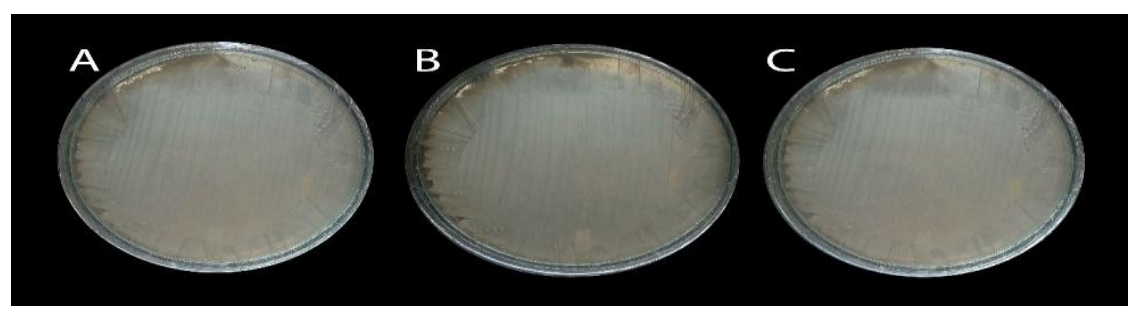

Figure 2b: E. coli Growth Control Plate at 24 hrs (A), 48 hrs (B), 72 hrs (C)

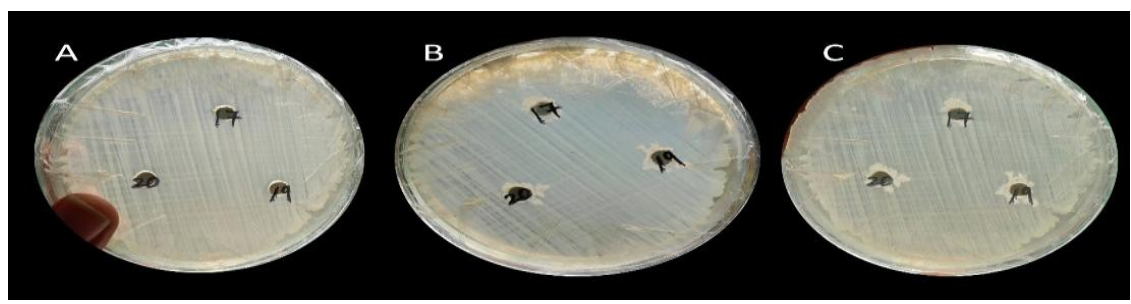

Figure 1: 17\%, 19\% \& 20\% NaCl containing plates of Staphylococcus aureusat $24 \mathrm{hrs}(\mathrm{A}), 48 \mathrm{hrs}(\mathrm{B})$,
$72 \mathrm{hrs}(\mathrm{C})$ 72 hrs (C)

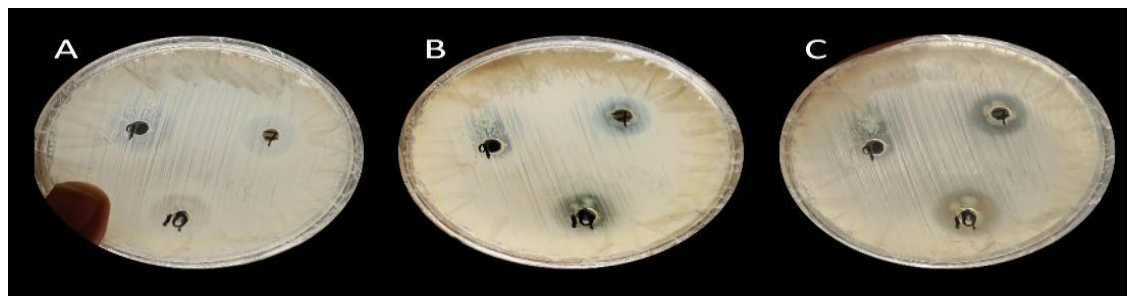

Figure 4: 7\%\&10\% SUCROSE containing plates of Staphylococcus aureus at $24 \mathrm{hrs}$ (A), $48 \mathrm{hrs}(\mathrm{B})$, 72 hrs (C)

EXHIBITION CURVES OF DIFFERENT

CONCENTRATIONS OF NACL SOLUTION AGAINST S.AUREUS

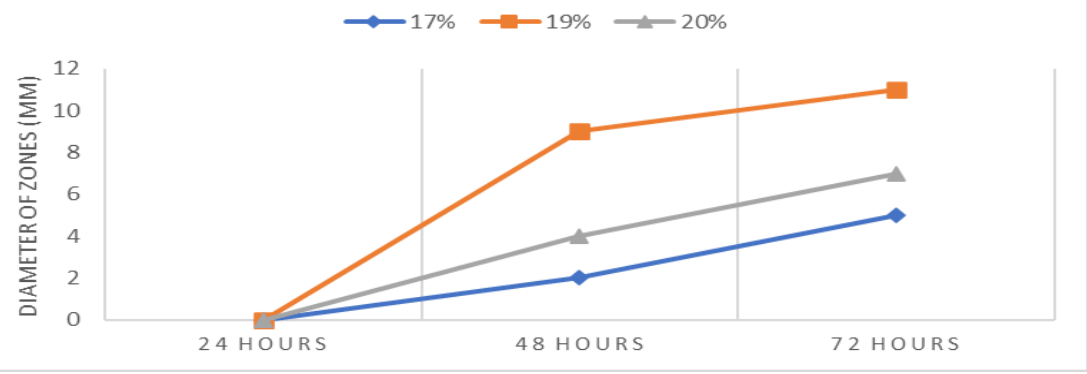

Figure 5: Exhibition curves of 17\%, 19\% \& $20 \% \mathrm{NaCl}$ solution against Staphylococcus aureus

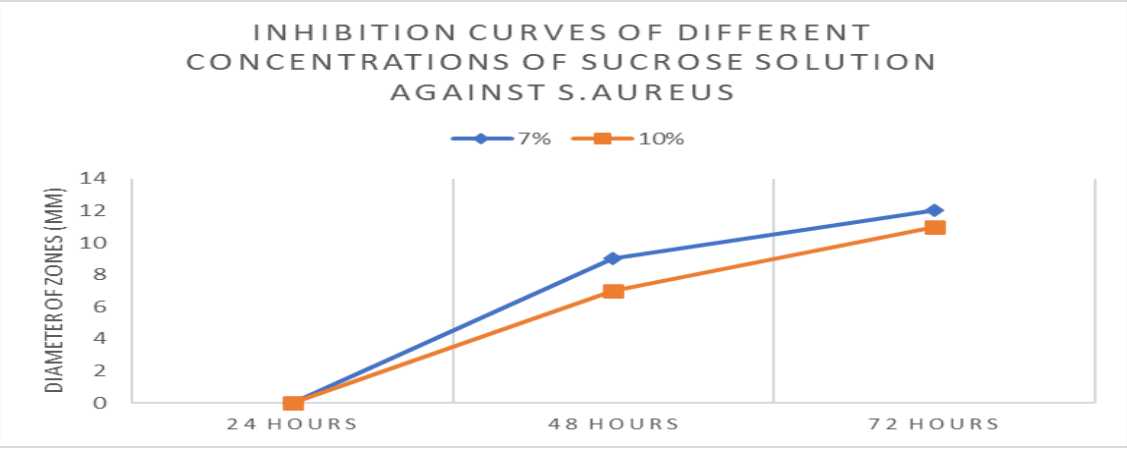

Figure 6: Inhibition curves of $7 \%$ \& $10 \%$ Sucrose solutions against Staphylococcus aureus 


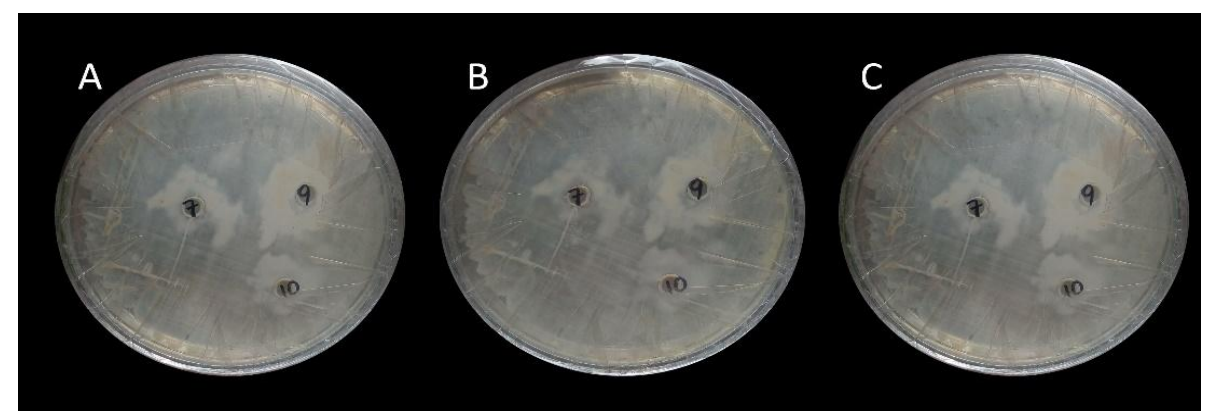

Figure 7: 7\%, 9\%\& 10\% SUCROSE containing plates of E. coli at $24 \mathrm{hrs}(\mathrm{A}), 48 \mathrm{hrs}$ (B), $72 \mathrm{hrs}$ (C)

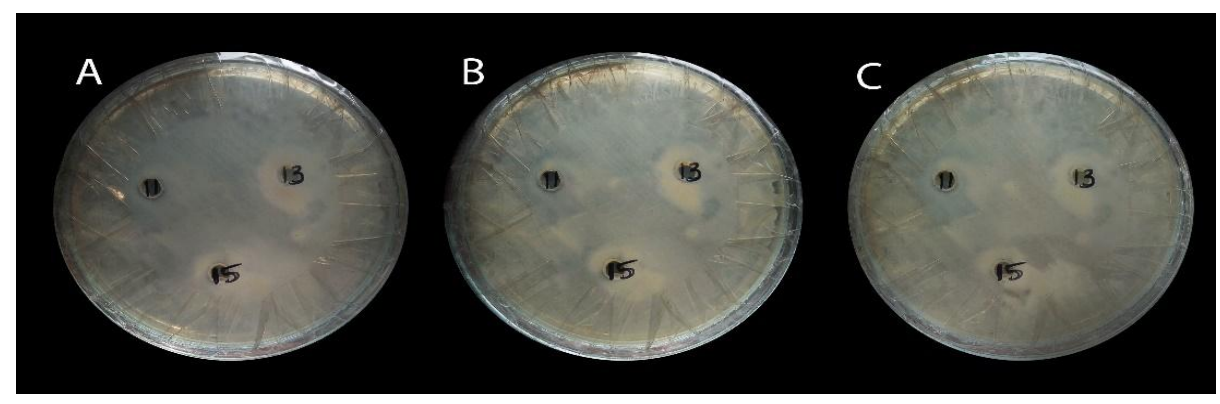

Figure 8: 11\%, 13\% \& 15\% SUCROSE containing plates of Staphylococcus aureus at 24 hrs (A), 48 hrs (B), 72 hrs (C)

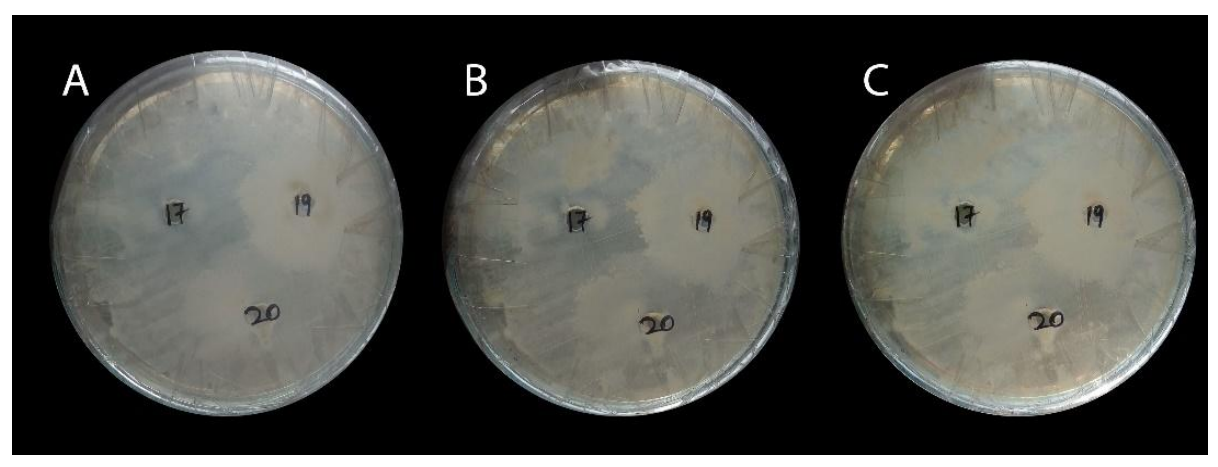

Figure 9: $17 \%, 19 \% \& 20 \%$ SUCROSE containing plates of Staphylococcus aureus at $24 \mathrm{hrs}(\mathrm{A}), 48 \mathrm{hrs}(\mathrm{B}), 72 \mathrm{hrs}$ (C)

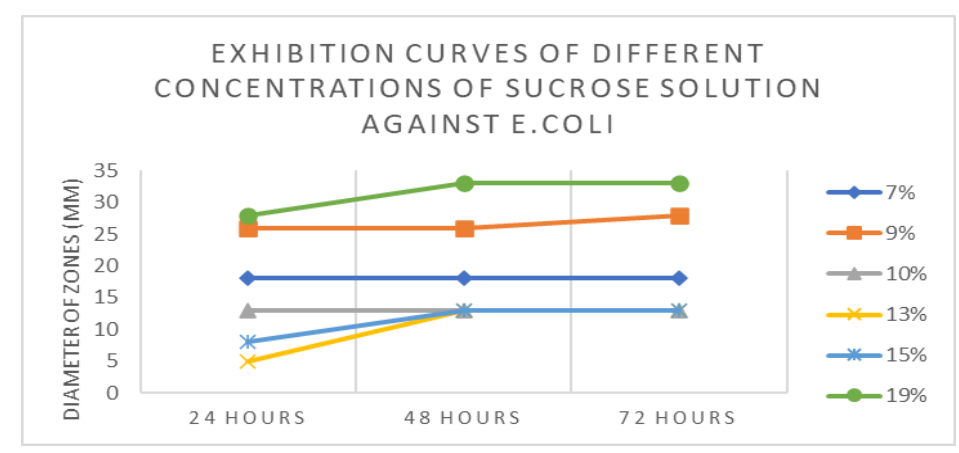

Figure 10: Exhibition curves of 7\%, 9\%, 10\%, 13\%, 15\%\&19\% Sucrose solution against E. coli 


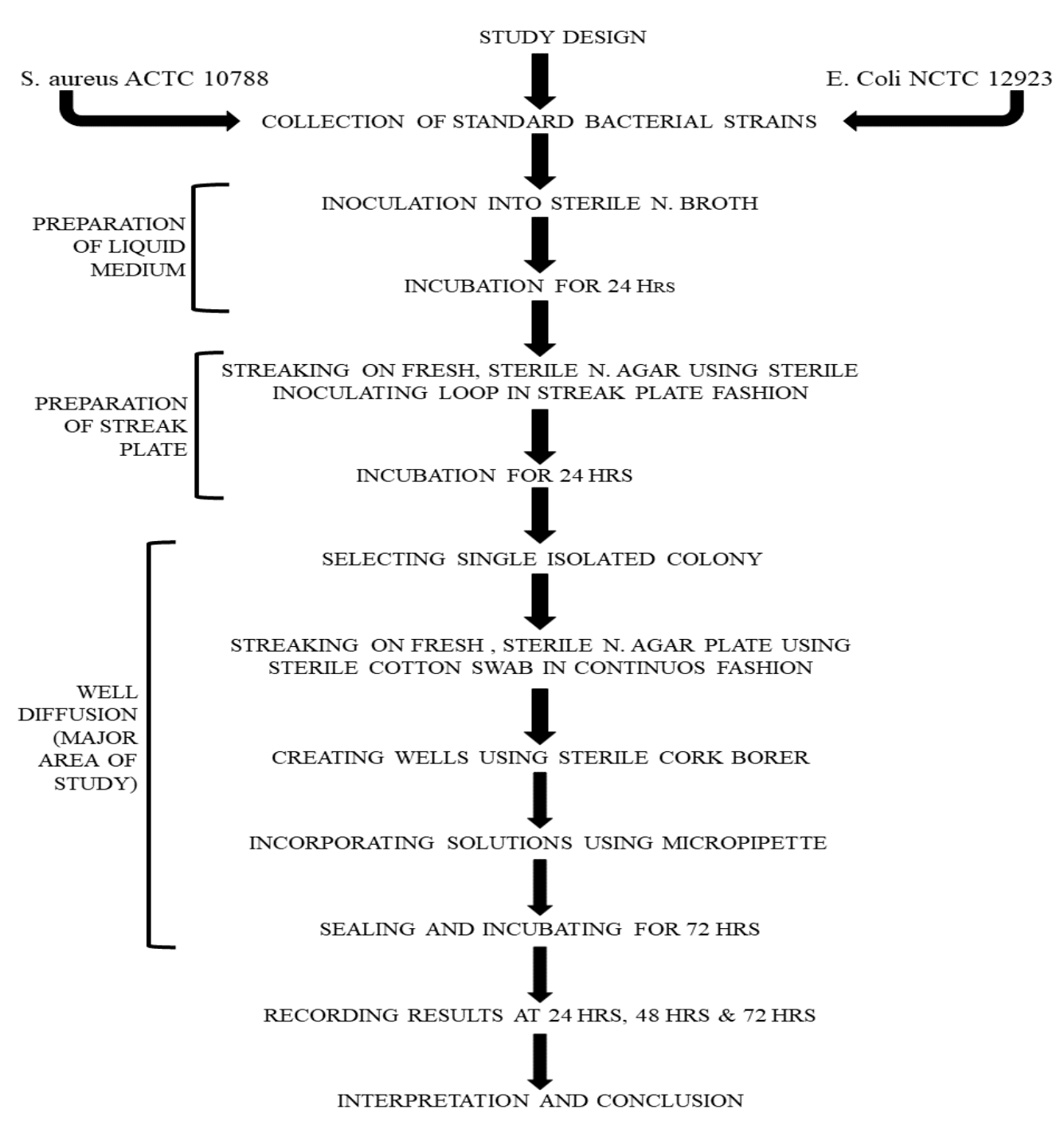

Figure 11: Step wise flow chart of study

But in case with Sucrose solutions,7\%, 9\%, $10 \%, 13 \%, 15 \%$ and $19 \%$ solutions developed $\mathrm{ZOE}$ at $24 \mathrm{hrs}$ and maintained a constant diameter at all the 3 points of measurements i.e., $24 \mathrm{hrs}, 48 \mathrm{hrs}$ and $72 \mathrm{hrs}$, except in case of $13 \%, 15 \%$ and $19 \%$ in which an increase is observed from $24 \mathrm{hrs}$ to $48 \mathrm{hrs}$ and remained the same till $72 \mathrm{hrs}$, as seen in figure $7,8 \& 9$ at $24 \mathrm{hrs}$ as A, at $48 \mathrm{hrs}$ as B and at $72 \mathrm{hrs}$ as C. The exhibition curves of this sucrose solution against E. coli are shown in figure
10. Results of all the concentrations of both $\mathrm{NaCl} \&$ Sucrose solutions, in terms of diameter of the zone expressed in $\mathrm{mm}$, is tabulated in the table 1 .

In conclusions in vitro study of effect of $\mathrm{NaCl}$ $\&$ Sucrose (solutions at different concentration ranges) on bacterial growth revealed that none of those has an inhibitory activity except for $7 \%$ and $10 \%$ sucrose solutions against Staphylococcus. Instead, 
they have exhibitory activity at maximum no. of concentrations. Hence the use of these solutions to combat with the growth of $S$. aureus and $E$. coli in case of superficial infections or injuries is not suggested. However, the same is to be checked in animal model to make sure that the above solutions in corresponding concentration ranges has an effect of bacterial growth exhibition and to be contraindicated in case of any superficial infections or injuries. But as we know that, $\mathrm{NaCl}$ is used as a preservative in food and pharmaceutical industries, it is advised that $\mathrm{NaCl}$ of above-mentioned concentrations (those which showed exhibitory effect) are not used to prolong the self-life of the product being prepared.

\section{Acknowledgement}

We sincerely thank and appreciate the guidance of our professor $\mathrm{T}$. Indira Priyadarshini, for her support and encouragement.

\section{Conflict of interest}

The author declares no conflict of interest.

\section{References}

Balouiri M, Sadiki M, Ibnsouda SK. Methods for in vitro evaluating antimicrobial activity: A review. Journal of pharmaceutical analysis. 2016 Apr 1; 6(2): 71-9.

Mondal S, Kolhapure SA. Evaluation of the antimicrobial efficacy and safety of pure hands herbal hand sanitizer in hand hygiene and on inanimate objects. Antiseptic. 2004;101:55-7.

Bagul US, Sivakumar SM. Antibiotic susceptibility testing: A review on current practices. Int J Pharm. 2016; 6(3): 11-7.

Gavin JJ. Analytical Microbiology: II. The Diffusion Methods. Applied Microbiology. 1957 Jan; 5(1): 25.

Mandal MD, Mandal S. Honey: its medicinal property and antibacterial activity. Asian Pacific journal of tropical biomedicine. 2011 Apr 1; 1(2): 154-60.

Coutinho HD, Costa JG, Lima EO, FalcãoSilva VS, Siqueira-Júnior JP. Enhancement of the antibiotic activity against a multiresistant Escherichia coli by Mentha arvensis L. and chlorpromazine. Chemotherapy. 2008;54(4):328-30.

Rodrigues FF, Oliveira LG, Rodrigues FF, Saraiva ME, Almeida SC, Cabral ME, Campos AR, Costa JG. Chemical composition, antibacterial and antifungal activities of essential oil from Cordia verbenacea DC leaves. Pharmacognosy research. 2012 Jul;4(3):161

Gul P, Bakht J. Antimicrobial activity of turmeric extract and its potential use in food industry. Journal of food science and technology. 2015 Apr 1; 52(4): 2272-9

Praditya D, Kirchhoff L, Brüning J, Rachmawati H, Steinmann J, Steinmann E. Anti-infective properties of the golden spice curcumin. Frontiers in microbiology. 2019 May 3; 10: 912.

\section{How to cite this article:}

Nithish, S., M. Anvesh, A. Rishitha Sanjana, R. Usha Rani, R. Pranay, A. Vydhika, P. Nikitha, D. Sowjanya, M. Ramya, K. Shiva and Indira Priyadarshini, T. 2021. An in vitro Study of Effect of Salt and Sugar on Bacterial Species. Int.J.Curr.Microbiol.App.Sci. 10(02): 10341042. doi: https://doi.org/10.20546/ijcmas.2021.1002.122 